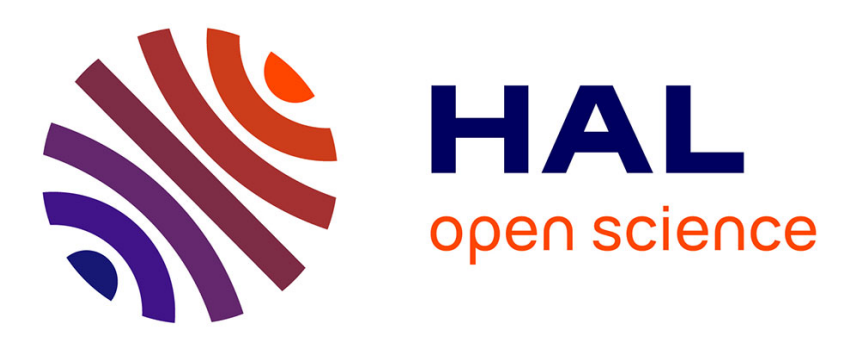

\title{
Reaching readiness in technological change through the application of capability maturity models principals
}

\author{
Olivier Zephir, Stéphanie Minel
}

\section{To cite this version:}

Olivier Zephir, Stéphanie Minel. Reaching readiness in technological change through the application of capability maturity models principals. CE’07, Jul 2007, Brazil. pp.57-64. hal-00305350

\author{
HAL Id: hal-00305350 \\ https://hal.science/hal-00305350
}

Submitted on 24 Jul 2008

HAL is a multi-disciplinary open access archive for the deposit and dissemination of scientific research documents, whether they are published or not. The documents may come from teaching and research institutions in France or abroad, or from public or private research centers.
L'archive ouverte pluridisciplinaire HAL, est destinée au dépôt et à la diffusion de documents scientifiques de niveau recherche, publiés ou non, émanant des établissements d'enseignement et de recherche français ou étrangers, des laboratoires publics ou privés. 


\title{
Reaching readiness in technological change through the application of capability maturity models principals
}

\author{
Olivier Zephir ${ }^{\mathrm{a}, 1}$, Stéphanie Minel ${ }^{\mathrm{a}, \mathrm{b}}$ \\ ${ }^{\mathrm{a}}$ LIPSI/ ESTIA- Technopôle Izarbel- 64210 Bidart. \\ bIMS, UMR 5218 CNRS, Univ-Bordeaux1 - 33405 Talence
}

\begin{abstract}
New technology introduction generally implies a change management plan as the adoption of advance technical capabilities comports information, cooperation and coordination restructuring. When planning for potential organizational developments the application of integrated design principals facilitates structure modelling. It enables to capitalize the perceived recommendations and constraints by the individuals impacted by change. Organizational structure design is considered as integrated product design where concurrent engineering principals are applied. The different professions concerned by process redesign, collaborate to its definition so as to ensure interoperability. This methodology allows considering the implied stakeholders at different level of the process and the needed resources to ensure readiness for a given technological change. As indicated by O.Poveda [9] even if the objective of this kind of methodology is clear, it remains complex to operate. The main difficulties are to translate the recommendations and constraints captured at the specifications phase to elaborate an optimal organizational structure supporting the new processes. In order to face these hurdles we propose a potential change maturity model so as to tackle the technical, social and strategic factors linked to organizational performance.
\end{abstract}

Keywords. Change management, Organizational development, Concurent engineering, Readiness for change, Change maturity models.

\section{Managing change as a constant}

Organizational change is often considered as a constant in contemporary firms. As Stated by A. Rondeau [10], there are multiple change sources linked to external environmental pressure such as worldwide competition, technological innovations and new norms and standards F.Pichault [8]. Enterprises are searching for methods and tools allowing productivity and innovation capability improvements. The productive system evolutions generate considerable functional transformations. ICT's developments contribute circumstantially to job transformation. These technologies accelerate some evolutions by replacing hierarchical systems by

\footnotetext{
${ }^{1}$ Olivier Zephir, LIPSI - ESTIA, Technopole Izarbel 64210 Bidart France ; Tel : +33 (0) 559438511 ; Fax : +33 (0) 559438405 ; $\quad$ Email : o.zephir@estia.fr
} 
network structures. The effects are that business actors have more operational autonomy and decisional power including an increase in transversal activities and collective data management. This kind of organization can be considered as complex. In fact the system is composed of multiple subsystems incorporating different professional corps cooperating to design and run the activity. It results to the fact that no unique profession can manage the global system as it is interconnected. Changing the organizational structure in this context is critical; a restructure of the collective activities must be operated while keeping day to day performance. Classical change management models describe transformation levels and steps that have to be reached to adopt new operational modes. In those models we cannot estimate the necessary capabilities that are needed by structured organizational agents to operate under a new mode. In order to measure the change capabilities we propose a combination of three evaluation models measuring information, cooperation and coordination transformation. The presented model which is developed in a European project provides a framework allowing project management teams to assess the organizational maturity to integrate new practices under structural or technological change.

\section{Maturity and readiness for change}

Maturity for change is defined here as workforce capability to operate effectively in transformed processes. In other words this methodology is addressed to tackle organization al readiness to fulfil business objectives through technological and structural improvements. As defined by Armenakis et al [1] readiness for organizational change is linked to the beliefs, attitudes and intentions of individuals regarding the organization's capacity to successfully undertake change. Our goal is to investigate the change capacity and specifically change capabilities. The proposed model integrates a set of evaluations structured in three main steps defined as maturity levels. The first level "Change Impact Mapping" is the step where departments, organizational actors and the relevant impacted core competencies are identified. The second level "As Is \& To Be State Comparison”, introduces evaluations characterising variables such as Cooperation, Coordination and Information form. These assessments allow capturing to which extent current work practices will evolve. The third level "Transformation Costs" provides an evaluation of the needed resources and support to simulate and introduce new work process. The innovative feature of this model is to integrate technical and human capability for organizational development. Few researches have been done both considering human and technological dimensions and activity performance. This paper does not answer to all organization al change problematic; nevertheless it brings a practical resource in process design. 


\section{SMMART European Project}

SMMART (System for Mobile Maintenance Accessible in real Time) in an integrated European project programmed on a three year period launched on November 2005. The consortium integrates 24 industrial and research actors investigating RFID embedded system development in the transport industry. Executed under the Framework Programme 6, the project is sponsored by the European Community. Aiming at enhancing the European leadership in the worldwide MRO (Maintenance Repair and Overhaul) sector, the project main objective is to provide usage and maintenance monitoring system technologically based on smart tags network. The tags will be designed to operate and communicate wirelessly in harsh environment such as vehicles propulsion unit. This network will enable the capture of usage and maintenance data through critical parts life cycle and secure end to end visibility of industrial and logistical supply chain. The application of this system would imply establishing new normative referential for the MRO stakeholders such as manufacturers, operators and regulation bodies and insurance companies. The general strategic stakes for the transport industry in investing in such research and development project is to decrease maintenance time in order to maximise operation time, to improve traceability of maintenance operations and operational safety. The introduction of these technological developments will include considering the needed reengineering of technical and human capabilities. Business process change will be necessary and the presented potential change maturity model is established as a support tool to ensure the SMMART technology deployment in industry.

\section{Potential change maturity model}

The term capability applied to organizations refers to the skills within a business structure that are relevant to managing a planned activity. The most suitable literal meaning taken from Oxford advance learners' dictionary 2004 for the term maturity is "fully grow or developed, having achieved one's full potential". We understand Capability Maturity Models as a method which allows a certain level of performance achievement prediction. One of the well known groups of Capability maturity model has been developed by the SEI (Software Engineering Institute) of the Carnegie-Mellon University. Theses models derive from Watts Humphreys original works, who introduced in the 1980's a model to improve software process development. Referring to CMMI Product Team [2] definition, maturity is perceived as "the extent to which an organization has explicitly and consistently deployed processes that are documented, managed, controlled and continually improved". There is a close relationship between capability and maturity they are both link to the quality improvement concept. Process maturity was born in the total quality management movement, where the application of statistical process control (SPC) techniques showed that improving the maturity of any technical process leads to two things: a reduction in the variability inherent in the process, and an improvement in the mean of performance of the process related to the capability [6]. Thus quality improvement consists in making process stable and 
enabling statistical control so as to maximize capability. A process can be said to be mature as it pass trough the stage from unstable to stable and then enjoying improved capability Cooke-Davies [3]. The CMM's that are available today cover project management processes, technical delivery processes for products and software development and organizational maturity. Among theses applications of CMM our objective is to inquire about change management capability and maturity. Change management is commonly incorporated in project management and generally defined as being a constant in project based organizations. Our main objective is to describe through a change management perspective how to determine the prerequisites to acquire a capability to incorporate a designed change. Considering change management within its theoretical or experimental literature, we observe few investigations on the readiness for change Lillian T. Eby et al. [6]. It is meant about readiness the extent to which an organization is capable to incorporate new business process and mastering them. The aim of the tool is to measure to which extent activity is going to be transformed. Structural and technological transformation due to process change can occur on different levels. Skills, knowledge and practices have to de readapted to react to the constant change. To resume introducing new technical process implies the consolidation of two factors. The former is ensuring the technical capacity to support the process and the latter is ensuring the capability of the impacted unit or profession to deliver a constant process. Mastering the potential change maturity is critical to accesses the organizational ability to monitor the service levels and ensure compliance with newly design corporate procedures and processes.

\subsection{Impact Mapping}

It is the first step where the impacts of the programmed change is characterised on the organizational activity. Through interviews the impacted processes and core competencies are determined. Core competencies as defined by Hammel et al [5] are those capabilities that are critical to a business, it embodies an organization's collective learning, the know how of coordinating diverse production skills and integrating multiple technologies. When the impacted core competencies are revealed, the link can be made to identify the teams and the individual competencies impacted. This step is crucial to fix the As Is state; it fixes the body of organizational knowledge and competencies that is concern by the change. The impacted process analysis reveals the related capability that is supported by the knowledge, skills and abilities employed by organizational actors to achieve the process goals and objectives. This level allows identifying "who" the organizational roles and functions and "what" competencies or tools, impacted [4]. The next figure illustrates an example of how organizational impacts are determined. Impacts on the general business workflow and the related processes or sub processes are identified. It allows considering the concerned teams or individuals. The last phase is to define the impacted factors which can be used to evaluate the needed recourses for change. 


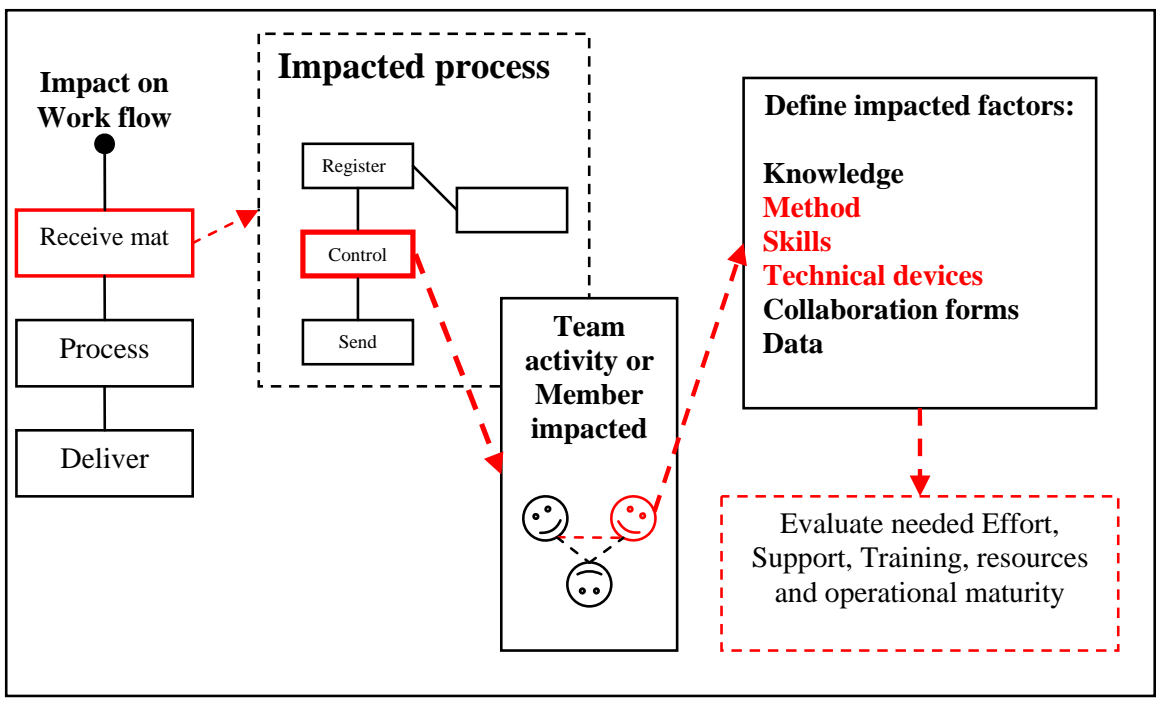

Figure 1. Impact Mapping

\subsection{As Is V/S To Be}

When the As-Is situation is set the To-Be one is designed considering all the impacted stakeholders in the various concerned processes. The Minel's [7] Cooperative Evaluation Scale (CES) is applied to characterise the level of collaboration between 2 professions involved in a same activity. Useldinger's [11] model defining as a six point Likert scale different levels of information is readapted to express the level of information change in an activity. Our investigation consists in the mapping of collaborating professions in the spotted impacted activities. We first carry an "As-Is" collaboration situation, to evaluate the level of cooperation before the change. Characterising the degree of cooperation allows defining targets related to change implementation. That is, when considering 2 professional corps collaborating, to determine if the same cooperative level is to be kept after change implementation or if it needs to be optimised. The Minel's CES considers 6 levels of collaboration, described by the level of knowledge shared by two interacting actors. The levels are as follows: 0 stands for no knowledge shared, 1 for common vocabulary, 2. Knowledge of concepts, 3. Knowledge of methods, 4. Master of domain, and 5 for expert of domain. Empirical studies show that in order to attain collaboration between two different professions, the level 3 of the CES is required to share a common vision of how to integrate the constrains of the other in ones own goals. Above this level, actors' specialised skills affect the cooperation. Under this level, cooperation is not efficient and can be improved. When the result of the "As Is" cooperation state is figured out, it has to be linked to the evaluation of the information changing state. 
This is carried out by using Useldinger's model where six level of information are defined as follows: Signal, data, information, knowledge, Skills and know-how.

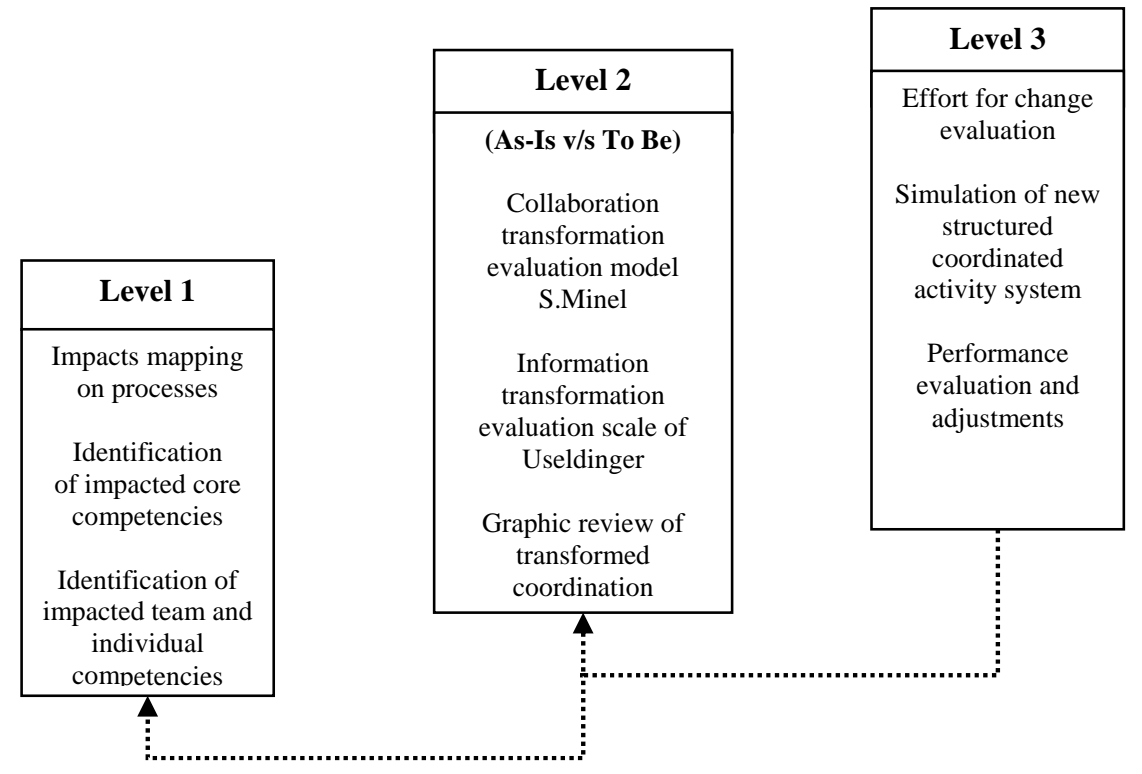

Figure 2. Potential Change Capability Maturity Model (O.Zéphir 2006)

The model is similar to a 6 point Likert scale characterising (under a hierarchy) the different levels of information throughout different formalized schemes. The collaborating actors have to define in common the level of information changing in their activities. Defining that, allows evaluating to what extent the activity is changing, from the form of data or structure to competencies and know-how. Having those information collaborating actors are able to redefine their common activities, and also to state the needed resources, effort and support they need to collaborate under a new operating scheme. A similar evaluation is applied to evaluate coordination evolution from the As-Is to the To-Be situation there is no particular method applied here, but and indication on each described collaboration activity.

\subsection{Effort for change evaluation}

This last step is design to indicate for each transformed activity spotted in the level two, the necessary human and technical resources to deliver a constant process. Once the extent to which activity is being transformed is fixed, as referred in CMM models, simulations are programmed to evaluate the needed documentation, management and control to reach continuous process improvement through readjustments. The prerequisite skills, knowledge, practices and tools to ensure compliance with the corporate procedures and process are fixed at this level. We 
estimate that readiness for change is reached when technical and human capability is estimated in relation to a define service level with improvement possibilities. Readiness means here the organizational capacity to incorporate new business processes and mastering there possible evolution.

\section{Future developments}

The presented Potential change maturity model is still in its development state. The first two levels are being actually tested and fine tuned through the SMMART European project. Theses first steps are crucial to determine the impacts of a new technology and the needed capabilities to support it. Change readiness definition relies circumstantially on the impacts definition. Applying capability maturity models principals to model the proposed method provides an efficient and practical framework to estimate the change project progression. Our next issue is to elaborate a strong simulation method so as provide reliable human capability evaluation. We still have to set the adequate method base on empirical researches analysis and strong theory evaluation. Our main focus trough this article was to present a practical model enabling the evaluation of the need capabilities in terms of human and technical capital for new technology introduction. Our investigations aim at conciliating human and technical factors for optimal process design.

\section{Acknowledgement:}

This work has been carried out within the SMMART (System for mobile Maintenance Accessible in Real Time) project that received research funding from the European Community's FP6.

\section{References:}

[1] Armenakis, A. A., Harris, S. G., \& Mossholder, K. W. Creating readiness for organizational change. Human Relations, 1993; 46(6), 681-703.

[2] CMMI Product Team. Capability maturity model integration (CMMI) Version 1.1. Pittsburgh, PA: Carnegie Mellon Software Engineering Institute, 2002.

[3] Cook-Davies J. Innovations, Project Management research, Measurement of organization al maturity, 2004.

[4] Deaming WE. Out of crisis. Massachusetts Institute of Technology, 2000.

[5] Hammel G., Prahalad CK. The core competence of the corporation, Harvard Business Review, 1990.

[6] Lillian T. Eby et al. Perceptions of organizational readiness for change: Factors related to employees' reactions to the implementation of team-based selling, Human relation, Tavistock InstituteJellinek EM, Vol 53, No. 3, 419-442 (2000).

[7] Minel S. Démarche de conception collaborative et proposition d'outils de transfert de données métiers, Ph.D. thesis, L’ENSAM Paris, 2003.

[8] Pichault F., Cornet A. Approches du changement et modes d'évaluation : la notion de performance revisitée, AGRH Poitiers 1996 
[9] Poveda O. Pilotage technique des projets d'ingénierie simultanée, modélisation des processus, analyse et instrumentation, Ph.D. thesis, l'Institut National Polytechnique de Grenoble, 2001.

[10] Rondeau A, Luc D. Transformer l'organization , Collection du savoir, Montréal, 2002.

[11] Useldinger $\mathrm{K}$. Contribution à l'analyse du comportement du décideur face aux systèmes d'aide à la décision, Ph.D. thesis, Nancy University, 2002. 